\section{Border occasionally seen between Light and Dark Regions on Photographic Plates.}

THE reason mentioned by Sir Oliver Lodge (p. 5) for the border seen between light and dark regions on photographs is not the only one. In the denser regions of a negative the developer gets more exhausted or restrained than in the thinner regions, and this affects the adjacent parts. At the junction of a dense and a thin area the edge of the thin part is made thinner by the restraining compounds (bromide, oxidised pyrogallol, \&c.) derived from the denser part, while, on the contrary, the edge of the denser part is made denser by the less exhausted developer flowing from the thin area. This effect is apt to be the more marked when the developer is already well restrained, as by staleness or the addition of much bromide.

Cambridge, November 4 .

F. J. Allen.

THE explanation of a well known phenomenon in photography, given by Sir Oliver Lodge in his letter to you last week (p. 5), does not take into consideration the following facts :-

(I) The "perceptible difference in thickness" between the acted-on and unacted-on portions of a negative is only perceptible to our unaided senses when certain developers are employed containing substances which act powerfully on the gelatin. Most modern negatives certainly have no perceptible difference in thickness, certainly not enough difference to give rise to so marked an effect as that referred to.

(2) The difference in thickness is most marked in the "carbon" transparencies from which many enlarged negatives are made. Here it can be both seen and felt; in the other case it cannot. We might therefore expect this cylindrical lens effect to be most marked when using such a transparency, but the careful comparison of a number of enlarged negatives made in these two methods reveals not the slightest difference between them.

In my own mind I have always accounted for the phenomenon in the following way:-The sensitive film ordinarily can only be approached by the developer from its outward face, hence the action over an area where the light action has been the same is uniform. But if that area is bordered by one where there has been little or no light action, the developer absorbed by such parts is not spent in doing any or much work in those parts, and, so far as any lateral diffusion is concerned, is practically fresh developer. Hence the borders of an exposed portion, where it comes against an unexposed portion, are attacked by fresh developer diffusing both from the front and from the unexposed part, and we should therefore expect to find a border line of greater density there, as in fact we do. For a similar reason we should expect to find a less dense line on the border of the more transparent portion, as is the case, though it is not often so noticeable as the former.

That this is the true explanation is, I think, made manifest by the fact that the line in question can be quite easily distinguished on plates exposed in Spurge's actinometer, where there is certainly no opportunity of a "cylindrical lens effect," and especially when development has been pushed far.

20 Tudor Street, London, E.C., November 6.

\section{The Use of Gasoline in Chemical and Fhysical} Laboratories.

EXPERIMENTAL work has so thoroughly established its claims to a reasonable share in the curriculum of every secondary school that very few schools are now without proper laboratories. No inconsiderable number of these schools are, however, beyond the limits of the ordinary gas supply, and the question of providing a substitute for coal-gas has presented no little difficulty. The matter became urgent some time ago at the Llanberis Intermediate School, mainly for heating purposes, but also for lighting. Investigation seemed to point to two possible substitutes-acetylene and gasoline. Both have been used, but not to any very large extent, in this country. An account was given in the School World for January rgoz, of the use of acetylene in Felsted School.
For a small installation, where light is the first consideration, it would probably be admitted that acetylene is highly satisfactory, but even for lighting the use of mantles has rendered gasoline a very severe rival. The problem is different when heat is the chief factor. In most cases of schools the gas is required to meet both demands, and gasoline seems to possess the advantage.

The questions for consideration are cost and efficiency.

In reference to cost, estimates were obtained to supply the chemical and physical laboratories and to light the whole building, and showed that the initial cost of plant and fitter's work would be about fifty per cent. higher for acetylene than for gasoline, and the estimated cost of maintenance for the former was also much higher.

Efficiency may be considered under the following heads:- (a) The relative simplicity of the generating plant; $(b)$ the ease of manipulation; $(c)$ the nearness to which the gas approaches in use to coal-gas; $(d)$ the risk of explosion.

(a) The plant used in the Llanberis School was supplied by the Walworth Manufacturing Co., of Boston, U.S.A., and consists essentially of three parts :-(1) A large shallow cylindrical copper tank, holding 250 gallons, buried some 30 feet or more from the building, which is filled with gasoline through a pipe and closed air-tight by a screw cap. Two other pipes, an inlet and outlet, are fitted into the top of the tank and pass under ground to the cellar of the building. (2) In the cellar a pump, worked by a weight on pulleys, forces air through the inlet pipe on to the surface of the gasoline in the tank. Evaporation is rapid (gasoline boiling from about $35^{\circ} \mathrm{C}$. to $70^{\circ} \mathrm{C}$.), and the mixture of vapour and air is driven through the outlet pipe into (3) an automatic mixer, by which a definite and known amount of air can be added, so that the proper proportion for burning may be constantly maintained. The whole plant is extremely simple, and was easily put up by a local gas-fitter under my direction.

(b) It requires very little attention. The weight has to be wound up about once a week; the mixer adjusted, by moving a small wheel along a rod, about once every two or three months; and the tank filled about every twelve or eighteen months. The frequency of the recurrence of these operations clearly depends on the size of the plant relative to the demands upon it.

(c) The burners differ slightly from the ordinary coal-gas bunsens, but give an excellent flame for ordinary laboratory purposes. The most noticeable difference is that the flame is more easily blown out. This gives a little trouble with an ordinary foot blowpipe, but a slight modification, which I hope to carry out, susgested by my friend $\mathrm{Mr}$. B. B. Turner, of Storrs Agricultural College, Connecticut (who has used gasoline for some years, and who brought it to my notice), will probably get over the difficulty. 'The plant supplies enough gas to light the whole building as well as for laboratory purposes.

(d) The risk of explosion is very slight, as any escape is at once detected by the strong smell, and the limits of explosion are narrower than those of coal-gas and very much narrower than those of acetylene. The absence of any heating arrangements to aid the evaporation, such as are proposed by some makers, considerably reduces the risk of explosion.

J. R. FosTer.

\section{THE AEGER IN THE RIVERS TRENT AND OUSE.}

H AVING had an opportunity of witnessing the bore, or aeger as it is locally called, in the River Trent at Gainsborough during the recent high equinoctial tides, which did so much damage all along the east coast, I send you the following description, which may interest some of your readers, more especially as I am not aware of any trustworthy account of this bore that has yet been published.

The Trent is a tributary of the Humber, and joins that river about 16 miles above Hull and 40 miles from the North Sea. The width of the Trent at the junction is from 2500 feet to 3000 feet at high water, diminishing to 700 feet $I_{\frac{1}{2}}$ miles from the 